\title{
Language and context; The Importance of their Interconnection in the Communication Process
}

\author{
Dr. Holta Heba, Dr. Klodiana Rafti, Msc. Romina Caushaj \\ Mediterranean University of Albania
}

\begin{abstract}
The power of language is enormous in terms of the life chain. For centuries it has been and remains the solution or complex of various human situations, so society constantly strives to give it meaning and place.The study aims to analyze the importance of language in the communicative process as well as its relation to context. Communicating means accepting that people think, act, and live differently and that only the meaningful conveyed message realizes the communication bridge between them.

The research question posed is: How important is the language / context connection in the communicative process between parties with disparate education, culture and beliefs?

The hypothesis of this research is: Language is an essential element in communication, related to sociocultural factors of society, therefore it cannot be perceived separately from the context in which it is used. The study consists of the treatment of language in space and time, based on some concrete examples of Albanian culture. Language, which enables the transmission of the meaningful message, is an important element of the communicative bridge between identities with disparate education and culture.
\end{abstract}

Keywords: language, communication, context, culture, identity. 


\section{SOCIAL SCIENCE, HUMANITIES \& EDUCATION}

\section{Introduction}

Language has served and continues to serve in conveying the legacy of identities, and is therefore indispensable in communicating in time and space. What makes a nation distinct from another, in the first point of view, is precisely the language. In the first phase of communication between two different identities, language is the first indication that we are communicating with a culture built on distinctly different beliefs, religions, histories and ideas. Human being since his beginnings until nowadays has created and developed based on spoken and written word. Stories have been transmitted and continue to be communicated through the centuries. Identities have resisted time through language. Cultures are developed through language. As an ever-evolving element, the word introduces every new phenomenon to human society a new meaning and expression, and as a constantly evolving element, it lies in the inevitable process of adaptation and renewal. This process never stops.

The methodology used in this research is: Screening analysis of the interaction of language and context in conveying a meaningful message during the communicative process between individuals of different cultures and backgrounds.

The objective of this research is the treatment of language and its interaction with elements of culture and human formation for the purpose of communication. Based on some concrete examples of Albanian culture, language will be treated as an element that develops and survives by adapting to the time and space in which it is written and spoken.

The human mind and hand need to be word-based to communicate and resist distances in space and time.

\section{Language and sociocultural elements.}

Language as an element structured to serve the message exchange occupies an important place in the communication sciences. Although not a single element, as there are many other elements of exchange such as body language and signs that are no less important in the communication process. It is true that it constitutes the main element of a culture of a particular nation but cannot 
6 - 8 MAive apart from the other sociocultural elements of all mankind. Communication transcends tanguage but also other structured systems (exchange, gifting, marriage systems, etc.) Oliver, B

2015, 23. One identity is different from another identity based on language. It indicates that one identity lives with the same linguistic codes within its type and determines that one identity has different linguistic codes than another. Linguistic co-existence makes it possible for people who speak the same language to communicate within their own kind without any difficulty on understanding. Each identity has its own linguistic norms, which determine that a specific language is spoken and written in a given context. When language is comprehensible within the species, then communication is realized and the members of the group interact with each other.

Language is influenced by political and social change. We recall here, many words that before the 90s in Albania were not used in the Albanian culture, because according to the socio-political spirit there were banned concepts and words of bourgeois culture. Words forbidden before the 90's> God, od, sir, mister.. etc. It couldn't be conceivable in those years to refer to someone with the term (o sir). These words began to be communicated in Albanian culture only after the 1990s when Albania underwent a radical change in the political and social system. Language develops simultaneously with the development of identity itself. ", We never have the right to be called a civilized nation, no matter how we learn foreign languages, because the nation is not civilized from learning foreign languages, but from learning its own language. ' (Shiroka, F.1989). Communicating correctly means understanding what you say and what others say to you. What is said needs to be interpreted through writing and speaking, so language is a primary element in the communication process.

Its language and use forms the personal identity of every human being, where the last one mentioned turns it into a necessity to communicate effectively with its like. Linguistic communication between individuals with background and formation from the same community is particularly important in the degree of message acquisition. Through language, the common cultural wealth of the people is transmitted over time, traditions are preserved and national culture further developed, giving appropriate homogeneity to the relevant national ethnic community (Shkurtaj, Gj, 2006. 23).

A particular social group identifies each of its members as part of its own language. The Albanian language identifies an Albanian as a member of the Albanian nationality. The ideal example would be the situation of an Albanian who is in the middle of America speaking English and suddenly hears someone speaking in Albanian. The first thought that comes to mind is: (He is like me! He speaks Albanian! He is Albanian!). The words and sentences in the Albanian language used by the individual in the middle of America, do nothing more except creating a 
It is precisely the language that wears you with identity, with a position in society, and with the labels that are acquired throughout the formation of the individual: Someone who speaks too much. Someone who speaks with no mistakes. Someone who speaks the official native language.

Someone who talks fast. Someone who speaks clearly. Someone who talks underneath his breath. Someone who doesn't know how to talk at all, etc.

The formal language and informal language in communication is a division, which is commonly used depending on the social context of the individual. Another distinction regarding language is the difference between the language of the educated and the uneducated. So, as is noted, language is an element that makes many social and class differences. The language used in public is not the same with the one used in everyday life in a close social circle.

In life, there are some moments where we have to choose the right words as we are forced to point out something that causes pain and that may actually be the last thing we would want to do in this world, but on the other hand we can't avoid it.

When communicating, the individual addresses an interlocutor, or an entire audience. In this case, he has to provide information, a detail, a tip, an explanation, or even an order. When telling a story, it is not the same as lecturing to provide convincing information, so arguing in linguistic communication remains essential. When giving information, a speaker or writer has a thesis to defend or a thesis to oppose. The thesis raised in oral or written communication is given in the form of lectures and needs to be based on arguments in order to stimulate debate and to convince the listener, the reader or the whole audience. As Chauradeau mentions in his work, "Argumentation is a dual-function lecture activity: telling a truth and persuading the reader of this.",l

In order to speak "argumentative language" the individual who writes or speaks, who departs for a particular purpose, must always develop a rationale in communication. It is clear that in a communication, where there is no argumentation, there is no protected thesis, and consequently the communication does not achieve the right result: obtaining and delivering accurate information.

${ }_{1}^{1}$ P. Chauradeau, Grammaire du sens et de l'expression, f. 785, Hachette, Paris, 1992. 


\section{SOCIAL SCIENCE, HUMANITIES \& EDUCATION} 6 - 8 MARCH 2029 times when we have to bite our tongue in order not to utter words that would words that would bring a never thought plan. All of these show the power of language in

communicating worldwide. The language of communication is the solution but also the complexity of the problem and yet it is worth mentioning the phrase: as the country is, so will the assembly be.

\section{Language in the right sense and place.}

Language becomes a symbolic part of human formation, but also finds its proper meaning depending on the context in which we are founded. It is seen as a necessity to create to tell the past, to create the present, and to build the future. A single word articulated in seconds can express the feelings, ancestry, and formation of an individual who has been remembered for years.

Clothing that refers to a concept or phenomenon should go in sync with the time and place when communicating. Everything labeled and communicated has a logical flow. An item is clad in words, then managed to be shown and communicated in time and space. As Carla Marello mentions in her book; "There is a logical continuum between the assertion of a word refers to something regardless of the context of the circumstance, the speaker's referencing of something identified in the context of the circumstance, and the reference to a part of the linguistic context." ${ }^{2}$ A stronger or softer intonation is enough, a tempered or momentary situation suffices, an aggravated or relieved emotional state is enough, and the word "I love you" takes on alienated meaning at different times and places.

It's not the same thing when you caress your child and say "I love you" every second. It is also not the same thing when you say to your boyfriend/girlfriend "I love you" ... A word only makes sense in context. Some find it very easy to express a feeling of love, while others find it difficult to write or pronounce it. Someone gives the word the right importance and one uses it in vain to cross the line. We all know that love is different and there are different kinds and forms of love.

In the sense that we want to give the word, of great importance is the interlocutor himself. It is not the same thing when we say 'good morning' to a work colleague we love and respect, with the good morning we give to a colleague we cannot bare but are obliged to greet, as we have no choice.

\footnotetext{
${ }^{2}$ Carla Marello, Anafora, in M. Garavelli, Il filo del discorso, faqe 149, Giappichelli, Torino, 1979.
} 

6 - 8 MARCH 2020 cultures is expressed in different forms, so we have come to the definitions that hear that the great desire to have someone nearby is pronounced "eat". For example; when someone wants to show how much he loves his girlfriend, he uses the phrase "I love you so

much I want to eat your heart". When someone tells them how much they like their girlfriend's eyes, use the phrase "I like your eyes so much I want to eat them". So great is this desire and love that it goes into hunger. When a stranger first hears it, he thinks that we are suffering from hunger and therefore we use this expression in jargon or cannibalism. The mere idea that the body's organs become edible, to show love and desire for someone, becomes meaningless to a stranger of another culture.

Another example is the comparison we make to the features of the Albanian female's face to show her beauty. In Albanian folklore, there are many songs, where the girl's lips are like cherry, the eye like olive, rosy cheeks like apples, etc.

Such as the mother's love for her child in popular jargon can cause misunderstanding to a stranger. The expression "I wish I could die how smart you are". In the literal translation of this expression, the stranger would be astonished at the fact that his mother would die if she had a smart child. Far be it if such a thing was to happen, we would even say; Such a happy mother I am to have a smart child as you in home.

As Saussure mentions in his work "Language is a treasure trove deposited by language practice and behavior in subjects belonging to the same community, a grammatical system potentially living in every mind or, more precisely in the brain of a whole body of individuals." 3

Understanding the associated word with actions also becomes more perceptible to the individual seeking to understand what we really intend to express. However, this is a way of expressing love and desire in our culture, and we often do not encounter it in everyday speech.

\section{Direct and indirect language (communication style)}

Different identities have different communication styles. Different cultures do not have and do not use the same style of communication. One can be very direct in the family context and less directly in the environment outside of that context. The person who communicates in style directly seeks to provide and receive information with the right interlocutor, who communicates intelligently well. It is not the case that the individual has to think of a particular style of

\footnotetext{
${ }^{3}$ Ferdinand, Saussure, Cours de linguistique generale, ED, Payot, Paris, 1962.
} 


\section{SOCIAL SCIENCE, HUMANITIES \& EDUCATION}

6 - 8 MARGH 2020, where he or she has to come up with the most accurate, or have to maintain a high tevel 20 ethics. For example: when an individual has to reach'out o a much wider audience than his or her family or friendly circle, he or she must make preparations for the message and the vocabulary he or she uses must not be the same. He has to choose the right words and gestures. Feeling comfortable, be more believable, cannot be done directly when speaking to a

general public, though the purpose of the speaker is to show that he is well prepared and has the situation at his fingertips.Direct communication is extremely easy and one person does not feel embarrassed if he or she is finding a favorable verbal or nonverbal language. Usually, this style of communication takes place in close, family-friendly surroundings. In this communication the emotion or stress is at zero level. Direct thoughts and ideas are said. The same intonation is preserved. There is no question if the right words are being used. The status of the individual facing is ignored. Speech rhythm can be slowed down or fasten up. When it comes to the direct communication style, it is clear that the sincerity of saying things comes into work here. Seen as a good communication policy, it is certainly widely used, but not always effective in different contexts. Being straightforward in what you say or do is a very important element of forming a human being, yet in many cases a straightforward style helps you achieve what you want. In many cases, it reveals to you what you think or the impression you have of a person other than you have in formation and conviction. In fact, depending on the person we are confronted with and what we want to achieve, it seems that the theory of personal space according to communication theorist Judee Burgoon is the right element, in terms of direct or indirect communication. "Personal space is defined as the varying volume of space around an individual and that determines that individual's preferred distance with others" (J, Burgoon, 1987, 129).

How can you tell it to a person directly whom you can't stand that he / she should stay away from you for his / her and your own good? Or how can you say it directly to an individual who loves him or her that he or she should be close to you for the benefit of both. In many cases when we communicate directly, without worrying about the feedback of the interlocutor, the risk of not achieving what we want is not small. The style of direct communication is congenial in character and in many contexts necessary, but there are often cases of misunderstanding. We often hear him say: I like that politician because he is straightforward and says things straight. But in a few cases this politician who says things out loud is taken as a low-luggage individual for not thinking about embellishing the message he has conveyed directly. And perhaps unintentionally, or intentionally, with this style of direct and honest communication has not gained the required harmony. By not being in sync with the listener's request, which may have been accustomed to saying things indirectly, the risk of missing out on the page is out of the question. 


\section{SOCIAL SCIENGE, HUMANITIES \& EDUGATION} 6 - 8 MA.RCW Her, there are many contexts where things cannot be said straightforwardly and direct style clarifying a problematic situation. At the moment he is very concerned about finding the right and persuasive words and sincerity is an element that does not work. He has to beautify the situation and follow the interlocutor's reaction at every word he uses.

He has to appear himself believable and beautiful in front of his listener, so he has to think twice about what he means. There has to be a perfect ethic in verbal and nonverbal communication in order to get the best out of the listener. The emotion and stress of being successful in indirect communication climbs above zero. This is precisely the moment when not all things can be said in a straightforward form, as depending on the extent of the problem, or the formation of the listener, the situation may worsen. The style of communication directly or indirectly varies from context to context and is a genuine indicator of the values of cultural groups. Context itself is an important part of the communication process. The use of direct and indirect style remains dependent on when communication occurs and on what we face. It is not wrong if you are used to one style of communication, to change to another style, in order to adapt to another culture not the same as yours. This is easily accomplished if the intention to communicate with it,is greater than the exit from the so-called "self".

Man is always in a dilemma when he has to choose to be social and reliable. To communicate directly and say things directly, or indirectly, by realizing the thought before expressing it to avoid negative feed-back?!

\section{Conclusions}

Language is closely linked to the political, economic and social organization of an identity. Stories, images, facts, factors, elements and all the nonverbal communication of an identity needs to rely on linguistic elements to be told or analyzed in the form of speech or writing. An unwritten and untold story would no longer be called such.

Language is also highly dependent on the cultural norms of the individual as well as the social context in which he is used. In different situations with different people different words are used to express the same concept or phenomenon. Pain, anger, hatred of love and many other phenomens cannot be expressed with the same words in different generations, formations and cultures. For this reason, language knowledge and its use are firstly closely related to the social context and secondly to the cognitive baggage of the individual. To the word we give the meaning and intonation we want depending on who we are and what we want to express. 


\section{$3^{\text {rd }}$ International Conference on}

\section{SOCIAL SCIENCE, HUMANITIES \& EDUGATION}

6 - 8 MARCHage has a very important role in terms of classifying the individual into a given social status. It determines whether the individual is dressed in prestige and stands up in the classes of society, or rather carries a negligible place and stands down.

Language remains the equipment that has helped and helps man to develop. In terms of the power and importance of the meaning it carries in harmonizing people's interactions in

communication, it is sufficient to mention the Albanian phrase: "Word bones do not have and bones it break". Humanity has created the word to express feeling and emotion, but we must not forget that the ones mentioned above are expressed in different forms by different identities, so the human psychic needs to be alert to use the right word at the right time for an accurate communication process.

\section{Bibliography}

Burgoon, J (1978), Acommunication Model of Personal Space Violations: Explication and intiala Test, Human Communication Research, Vol 4.

Carla Marello, Anafora, tek M. Garavelli, (1979) Il filo del discorso, Torino: Giappichelli.

De Saussure, F. (1962). Cours de linguistique génerale. Paris. Edition Payot.

Ollivier, B (2015) Shkencat e komunikimit. Tiranë, Papirus

Shkurtaj, Gj (2006). Kultura e Gjuhës. Tiranë: Botimet e librit Universitar.

Chauradeau,P. (1992) Grammaire du sens et de l'expression, Paris, Hachette. . 